$\xi=1$ 国

\title{
Vocabulary Learning Strategies of Saudi English Major Students: Strategy Use and Gender
}

\author{
Jamilah Al-Harbi ${ }^{1}$ \& Engku Haliza Engku Ibrahim ${ }^{1 *}$

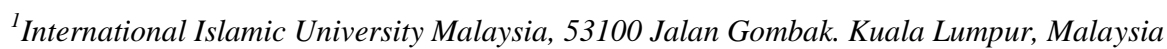 \\ *Corresponding author E-mail:ehaliza@iium.edu.my
}

\begin{abstract}
One of the major challenges that learners face during the process of foreign language learning is acquiring vocabulary. Thus, students need to employ various vocabulary learning strategies to acquire the vocabulary of a foreign language. The present study attempts to identify the vocabulary learning strategies employed by Saudi English major students. This study also aims to examine if there are differences between male and female students in the pattern and frequency of strategy use. Sixty-five first-year English major students of Majmaah University participated in the study. Their vocabulary learning strategies were measured using the Vocabulary Learning Strategy Survey. The results showed that students preferred cognitively less demanding strategies compared to the ones that required deeper cognitive processing. The most frequently used strategies were "I try to remember the word by repeating it for several times," "I try to guess the meaning of the word from text/context" and "I learn new words when I interact with native speakers." In general, social strategy is the most used strategy while memory strategy is the least used. The findings also showed that males preferred social strategy compared to females who preferred cognitive strategy and that two strategies (cognitive and memory strategies) showed significant differences between the two genders.
\end{abstract}

Keywords: Vocabulary learning strategies; EFL Saudi Learners; Vocabulary Learning Strategy Survey; Gender

\section{Introduction}

Vocabulary learning is an important component for ESL/EFL learners in order to learn a new language. No one is able to express himself clearly without the use of appropriate vocabulary. That is why, vocabulary learning strategies help a learner to a great extent in learning a new language $[1,2]$. Research in the field of vocabulary has moved from being a neglected backwater to a position of great importance. Over the past years, psychologists, linguists and language teachers have conducted many research of vocabulary learning techniques adopted by English language learners [3]. They have tried to identify the strategies that learners use to acquire new words or to remember them.

Vocabulary learning strategies are important. Schmitt, et. al. [4] found a strong relationship between vocabulary level and learning strategies. He further stated that learners' use of vocabulary learning strategies affects vocabulary acquisition. Gu [5] emphasises that learners' vocabulary learning processes can determine the overall success or failure of second language acquisition. According to Nation [6], it would be beneficial for teachers or language instructors to focus on explicit learning activities which could help them acquire the essential 2,000-3,000 words in the early phases of language acquisition. These learning activities can be used in both second language learning and foreign language learning especially when good language proficiency is expected, but learners are restricted by time.

A number of research has also been carried out on EFL and ESL learners' preferred strategies to learn the vocabulary of a foreign language [4-7]. For example, classified vocabulary learning strategies into word remembrance and new word learning. Also, Gu [8] introduced three vocabulary learning strategies: the cognitive strategies, the metacognitive strategies, and the memory strategies. Another classification of vocabulary learning strategies was addressed by Fan [7] who classified vocabulary learning strategies as the primary category strategies and the remembering category strategies. The primary category strategies involve strategies such as guessing and dictionary use. The remembering category strategies involve strategies such as analysis, repetition, grouping, and association.

Schmitt, et. al., [4] divided vocabulary learning strategies (VLS) into two main groups of Discovery strategies and Consolidation strategies. The first kind is used by students to discover new words. The second group of strategies, on the other hand, helps students to combine with other vocabulary items. Schmitt, et. al., [4] further categorised vocabulary learning strategies into five subcategories. The categories are Determination strategies, Social strategies, Memory strategies, Cognitive strategies and Metacognitive strategies. Determination strategies refer to a person's individual choice of strategy employed in learning new vocabulary. Conversely, social strategies help people to learn new words from social interactions in their day to day life. The third strategy is Memory strategy where a learner associates his schema or background knowledge with a new word. The next strategy, Cognitive strategy, focuses on mainly the mechanical techniques such as repetition, summarising or inferring the meaning of a new word. The final strategy is Metacognitive strategy which refers to how a person makes the decision of choosing a new word and thinks about the development of his language use in a particular context [4]. 
Integrating various classification systems into a single taxonomy, Schmitt, et. al. [4] developed a comprehensive taxonomy of VLS. This taxonomy was organized around Oxford's [9] metacognitive, cognitive, memory, and social classifications of L2 learning, and Nation's distinctions of discovery and consolidation strategies. (Table 1). This current research adopted the VLS definition by Schmitt et.al. [4].

Table 1: Taxonomy of L2 VLS ${ }^{[4]}$

\begin{tabular}{|l|l|}
\hline \multirow{2}{*}{ Discovery Strategies } & Determination Strategies \\
\cline { 2 - 2 } & Social Strategies \\
\hline \multirow{4}{*}{ Consolidation Strategies } & Social Strategies \\
\cline { 2 - 2 } & Memory Strategies \\
\cline { 2 - 2 } & Cognitive Strategies \\
\cline { 2 - 2 } & Metacognitive Strategies \\
\hline
\end{tabular}

\section{Literature Review}

\subsection{Vocabulary Learning Strategies}

Vocabulary knowledge is affected by the VLS employed by learners. Numerous studies have been carried out to evaluate the types of learning strategies employed by students. Alhaisoni [10] studied the type and frequency of language learning strategies used by 701 male and female EFL students studying in an intensive English language programme at the University of Ha'il. This study employed the Oxford Strategies Inventory of Language Learning (SILL) albeit with some modifications. The findings of this study revealed that there was a relationship between the use of language learning strategies (LLS) on one hand, and gender and proficiency level on the other. The study found that the students used low to medium frequency language learning strategies with a preference for cognitive and metacognitive strategies. However, there was no significant gender difference in terms of the use of language learning strategies except in the social strategies where females were found to be employing them more than their male counterparts.

Amirian et. al. [11] conducted a similar study on VLSs among 74 Iranian EAL students (18 males and 56 females; 56 undergraduate students and 18 postgraduate students) of tertiary level. They administered the VLS questionnaire developed by Schimitt, et. al. [4] and carried out semi-structured interviews. It was observed from the responses that the participants thought that they use the category of determination strategies more frequently than the remaining four strategies of the VLS. They also responded that the least utilised VLS was the category of social strategies. The authors noticed that the postgraduate students were more successful in language learning and they tended to use a wide range of VLSs instead of just memorisation.

\subsection{Popular and Unpopular VLSs}

Many research have also been carried out to find out the most used VLS by learners. Schmitt, et. al. [4], in their study of 600 Japanese students from junior and senior high schools found that there was a match between the actual use of VLS and perceived helpfulness of VLS by the students. The strategies of learning new vocabulary items that the students preferred were "consulting a bilingual dictionary," "verbal repetition," "written repetition," "studying the spelling," and "guessing from context." In contrast, strategies such as using "physical action," "L1 cognates," "keyword method," and "semantic maps" were not utilized much. In addition, similar results were found regarding the perceived helpfulness of the strategies. The students used some of the strategies of learning vocabulary more frequently which were generally considered to be helpful for all. Schmitt, et. al. [4] also mentioned the that the VLS learners use differ according to their age. Kudo [12] conducted a study on 504 Japanesse senior high school students and found that they did not use the strategies that demanded more cognitive strength such as semantic mapping or keyword method. Instead, their learners preferred the shallower strategies that take less time to learn a new word such as verbal and written repetition of vocabulary items.

Similarly, first year university students learning English as a foreign language in Saudi Arabia also showed a preference for the cognitively shallower strategies of using verbal and written repetition for learning new words (Al-Nujaidi [14]). these results were to some extent reflecting the findings of the studies conducted by Schmitt, et.al. [4] and Kobayashi [15]. On the other hand, a study of 15 Australian students found that their learners preferred repetition of new words and reading about its meaning from dictionary-like entries for learning Italian which was identified by using a think-aloud protocol. They rarely used any difficult cognitive vocabulary learning strategy Lawson, et.al. [16].

Conversely, strategies such as "using bilingual dictionary" and "making a list of new words and memorising" were among the six most commonly used VLS among 934 EFL Turkish university students (Sahbazian [17]). These learners did not use strategies such as "asking someone the meaning of new word" and "use semantic mapping" frequently. Jun-Eon Park (2001) conducted a study among 600 Korean EFL Learners of different age groups at the elementary school, middle school, high school and tertiary level. The three vocabulary learning strategies the participants selected were "using bilingual dictionary", "guessing the meaning from the context," and "asking classmates or friends for the meaning." In addition, they also adopted strategies such as "studying the sound of a word," "saying the new word aloud when studying," and "remembering the spelling a word" most frequently for understanding of meaning. A similar joint research by Lee [34] reported that Korean EFL high school students employed the strategies of "using bilingual dictionaries," "guessing from textual context," and "analyzing affixes and roots". They also used strategies such as "saying it aloud," "studying its spelling," and "paraphrasing its meaning" for understanding the meaning of the word. Thus what can be observed from the research carried out is that learners employ a variation of strategies and that no one strategy was found to be vastly preferred.

\subsection{Vocabulary and Gender Differences}

Scholars have pursued research on gender differences and its influence on second language acquisition in case of reading comprehension and learning strategies [18-20]. The results of these studies showed contradictory findings because some of them showed that male learners have a higher capacity of learning a foreign language than their female counterparts. Others emphasise females being better language learners than males, and still some others demonstrate that gender is not significant in second or foreign language acquisition.

Similarly, a greater interest was observed among recent research to examine the influence of gender roles on several dimensions related to lexical knowledge. A number of studies have examined receptive and productive vocabulary knowledge of learners, and have reached different conclusions. Lin, et. al., [21]; Lynn, et. al., [22] \& Edelenbos, et. al., [23] point out that males perform much better than the female learners in the acquisition of new vocabulary items. On the other hand, in the studies of Nyikos [24] and Sunderland [25], females were found to be better in memorising German language vocabulary.

In contrast, there were studies that did not find any difference in gender in learning vocabulary items in receptive vocabulary test [26-27]. However, Jiménez, et. al. [28] pointed out that female learners perform better than males in productive vocabularies. AlNujaidi [13] found that gender plays quite a unique role in deter- 
mining which VLS was chosen. His results showed that male students preferred knowing a word's meaning by memorising its definition more than the female learners. On the other hand, female learners preferred using a new word in a context and understanding its meaning.

Additionally, a significant number of female respondents performed better in a test of lexical availability consisting of 15 cues (Catalán, et. al., [29]). A compilation of studies on gender roles on vocabulary acquisition display mixed results of male and female vocabulary performance (Jiménez, et. al., [30]). Sunderland [25] suggests that the relationships between vocabulary and gender are not enduring, but may be context and test type-specific with other "third factors" such as L1, age or L2 proficiency influencing them. Therefore, gender is acknowledged as a complex and nuanced issue.

Likewise, regarding the role of gender in vocabulary learning strategies, Catalan [20] observes that females employ a wider range of strategies in acquiring and using new vocabulary items making them more successful in language acquisition compared to males. Grace [31] also concludes that there are differences in the strategies used by members of both genders, although she reports similar results for both genders for receptive vocabulary knowledge and retention rate.

The above sub-section has made it evident that various cases have been studied in relation to VLS and its relation to gender, language acquisition and proficiency. These studies reviewed have employed different methods in drawing their conclusions.

\subsection{Theoretical Framework}

The VLS taxonomy employed in this present study was adapted from Schmitt, et.al. [4] which could be basically divided into two dimensions of discovery and consolidation strategies of vocabulary learning. Discovery strategies include determination and social strategies, whereas consolidation strategies comprise of social, memory, cognitive, and metacognitive strategies. Social strategies focus on learners' interaction with other people in the society, memory strategies combine existing knowledge with new vocabulary. In addition, cognitive strategies help them to learn vocabulary by using images, repetition, organising new language and other forms of making meaning. A total of 58 strategies were included which were based on the taxonomy of language learning strategies. Accordingly, this taxonomy is 'currently the most complete typology' (p. 67) of vocabulary learning strategies.

Previous studies in this field revealed the significance of vocabulary learning in language acquisition. Schmitt, et. al. [4] \& Ahmed [32] proposed a scale for the strategies of vocabulary learning taking into consideration their potential to contribute to the expansion of vocabulary knowledge. Thus, this study assumes that Saudi university EFL students ought to give higher priority to strategies for vocabulary learning in their language acquisition.

The purpose of this study was to identify the VLS employed by Saudi English major students. It also aims to examine the differences between male and female Saudi English major students in the pattern and frequency of strategy use. The specific research questions are:

i. What are the most and least frequently used vocabulary learning strategies of Saudi first year EFL university students?

ii. Is there any gender difference in the pattern and frequency of strategy use?

\section{Methodology}

\subsection{Participants}

The participants of this study were sixty five (65) Saudi EFL learners of Majmaah University. The participants were 18 to 22 years old. $51 \%(n=33)$ of the participants were males and $49 \%$ $(n=32)$ were females. All were first year English major students.

\subsection{Instrument}

\subsubsection{Vocabulary Learning Strategies Questionnaire (VLSQ)}

The survey for this study was adopted from Schmitt, et. al. [4] to identify the VLS employed by Saudi students. VLSQ has been used by researchers extensively for its easily adaptable characteristic. VLSQ has also been proven to be suitable for students of any educational background and target language, and comparable to other research of the field (Catalan [20] \& Ruutmets [33]). The questionnaire focussed on two dimensions; the discovery and consolidation strategies of vocabulary learning. Discovery strategies include determination and social strategies, whereas consolidation strategies comprise of social, memory, cognitive, and metacognitive strategies. A total of 58 strategies were included in the VLSQ which are based on the taxonomy of language learning strategies.

\section{Findings and Discussion}

RQ1: What are the most and least frequently used vocabulary learning strategy of Saudi first year EFL students?

Table 2 shows the means and standard deviation of VLS. The grouping of items in the survey was based on the degree of frequency according to the suggestion by Oxford [9]. Based on the table, items "I try to remember the word by repeating it several times", "I try to guess the meaning of the word form text/context" and "I learn new words when I interact with native-speakers" were the strategies with the highest frequency of use among respondents. Apart from the above strategies, verbal and written repetition strategies were next in terms of frequency of use. The findings of the current study were coherent with the findings of Schmitt, et. al. [4] where "say a word aloud", "study the spelling, and "written and verbal repetitions" strategies were found to be the preferred choice of the respondents when consolidating the meaning of unfamiliar vocabulary.

Though it may be too hasty to generalise such attitude of first year Saudi students majoring in English, but it is seemingly true that using strategies that are cognitively less demanding such as those of verbal and written repetition is more common among participants of this study when compared to using cognitively demanding strategies such as the keyword method. This could be due to the learning and instructional fashion adopted in the school system which may urge students to focus on memorising new vocabulary and repeat them (for example, spelling lessons, loudly uttering new words, and the study of word sounds).

Table 2: Use of VLS in General

\begin{tabular}{|l|l|l|l|}
\hline Item & & M & SD \\
\hline $\begin{array}{l}\text { High Usage (M=3.8 or above) } \\
\text { I try to remember the word by repeating it } \\
\text { everal times }\end{array}$ & COG1 & 4.3 & 0.9 \\
\hline $\begin{array}{l}\text { I try to guess the meaning of the word form } \\
\text { text/context }\end{array}$ & DET5 & 4.3 & 1.0 \\
\hline $\begin{array}{l}\text { I learn new words when I interact with native- } \\
\text { speakers }\end{array}$ & SOC7 & 4.2 & 1.1 \\
\hline $\begin{array}{l}\text { I try to remember the word by writing it repeat- } \\
\text { edly }\end{array}$ & COG2 & 4.1 & 1.0 \\
\hline I discover new words and their meanings through & SOC4 & 4.0 & 0.6 \\
\hline
\end{tabular}




\begin{tabular}{|c|c|c|c|}
\hline oup v & & & \\
\hline $\begin{array}{l}\text { I use new words in sentences and in conversions } \\
\text { so I can remember them }\end{array}$ & MEM12 & 3.9 & 1.3 \\
\hline $\begin{array}{l}\text { I use the English-language media (songs, movies, } \\
\text { newscasts, etc.) }\end{array}$ & MET1 & 3.9 & 1.3 \\
\hline $\begin{array}{l}\text { I create a mental image of the new meaning of a } \\
\text { word }\end{array}$ & MEM2 & 3.8 & 1.2 \\
\hline I ask my classmates or friends for meanings & SOC3 & 3.8 & 1.2 \\
\hline $\begin{array}{l}\text { I connect a word to my personal experience to } \\
\text { remember it }\end{array}$ & MEM3 & 3.8 & 1.3 \\
\hline $\begin{array}{l}\text { I connect a word with this synonym (large-big) } \\
\text { and antonym (big-small) }\end{array}$ & MEM5 & 3.7 & 1.1 \\
\hline $\begin{array}{l}\text { I memorize the words by reading it aloud while } \\
\text { studying }\end{array}$ & MEM16 & 3.7 & 1.1 \\
\hline I keep a vocabulary notebook & COG9 & 3.6 & 1.2 \\
\hline I remember words together that sound similar & MEM9 & 3.6 & 1.0 \\
\hline $\begin{array}{l}\text { I remember a new word by remembering its } \\
\text { location on a page, on a board or a street sign } \\
\text { where I first saw it or heard it }\end{array}$ & MEM15 & 3.6 & 1.2 \\
\hline $\begin{array}{l}\text { I analyse any available pictures or gestures } \\
\text { (signals) }\end{array}$ & DET4 & 3.6 & 1.0 \\
\hline $\begin{array}{l}\text { I analyse words in terms of parts of speech e.g.: } \\
\text { verb, noun }\end{array}$ & DET1 & 3.6 & 1.0 \\
\hline $\begin{array}{l}\text { I group words together to study them (animals, } \\
\text { names, fruits.....etc.) }\end{array}$ & MEM10 & 3.5 & 1.2 \\
\hline I paraphrase the meaning of the word & MEM23 & 3.5 & 1.0 \\
\hline $\begin{array}{l}\text { I study a word with a pictorial representation of } \\
\text { its meaning (associate new words with objects) }\end{array}$ & MEM1 & 3.5 & 1.3 \\
\hline Low Usage $(\mathrm{M}=2.4$ or below $)$ & & & \\
\hline I use physical action when learning a word & MEM26 & 2.4 & 1.1 \\
\hline I put English labels on physical objects & COG8 & 2.4 & 1.2 \\
\hline I use semantic feature grids & MEM27 & 2.3 & 1.0 \\
\hline I use monolingual dictionary (English-English) & DET7 & 2.3 & 1.5 \\
\hline $\begin{array}{l}\text { I ask my English instructor to check my flash } \\
\text { cards or word list }\end{array}$ & SOC6 & 2.3 & 1.2 \\
\hline
\end{tabular}

Nonetheless, strategies such as "I ask my English instructor to check my flash cards or word list", "I used a monolingual dictionary (English-English)", and "I use semantic feature grids" were among the least frequently used strategies. This result could be attributed to the fact that flash cards and images are less popularly used in Saudi in English learning classrooms. In addition, preparing flash cards and images could be tiring for students. Item "I use monolingual dictionary (English-English)" was not popular among the participants. This could be related to the findings of Nation [6] which stateted that it may be difficult for learners to use monolingual dictionaries as "although most monolingual dictionaries use a controlled vocabulary in their definitions, a learner has to know this vocabulary and has to be able to cope with the grammatical difficulties of the explanation" (p. 290). Indeed, many studies have shown that L2 learners preferred bilingual dictionaries (Schmitt, et. al., [4]; Kudo [12]; Sahbazian [17] \& Lee [34]).

Table 3: Descriptive Statistics of Each Category of the Strategies

\begin{tabular}{|l|l|l|l|}
\hline \multicolumn{1}{|c|}{ Strategy Type } & Mean & SD & \multicolumn{1}{c|}{ Rank } \\
\hline Social Strategy & 3.48 & 1.082 & 1 \\
\hline Determinant Strategy & 3.23 & 0.675 & 4 \\
\hline Cognitive Strategy & 3.32 & 0.801 & 3 \\
\hline Meta-Cognitive Strategy & 3.33 & 0.768 & 2 \\
\hline Memory Strategy & 3.20 & 0.644 & 5 \\
\hline
\end{tabular}

Table 3 and Figure 1 show all the sub-categories of both Discovery and Consolidating meaning categories used by the learners. Social strategy $(\mathrm{M}=3.48, \mathrm{SD} 1.083)$ is ranked the highest in the table while the memory strategy $(\mathrm{M}=3.21, \mathrm{SD}=6.44)$ is ranked the lowest of them all. Meta-cognitive strategy $(\mathrm{M}=3.34, \mathrm{SD}=.770)$, cognitive strategy $(\mathrm{M}=3.32, \mathrm{SD}-.802)$, and determinant strategy $(\mathrm{M}=3.23, \mathrm{SD}=.686)$ take the middle range of mean score in the table which is ranked $2 \mathrm{nd}$, 3rd and 4th respectively. This result may stem from learner's conception that learning vocabulary has mainly to do with cognitive practice and memorisation.

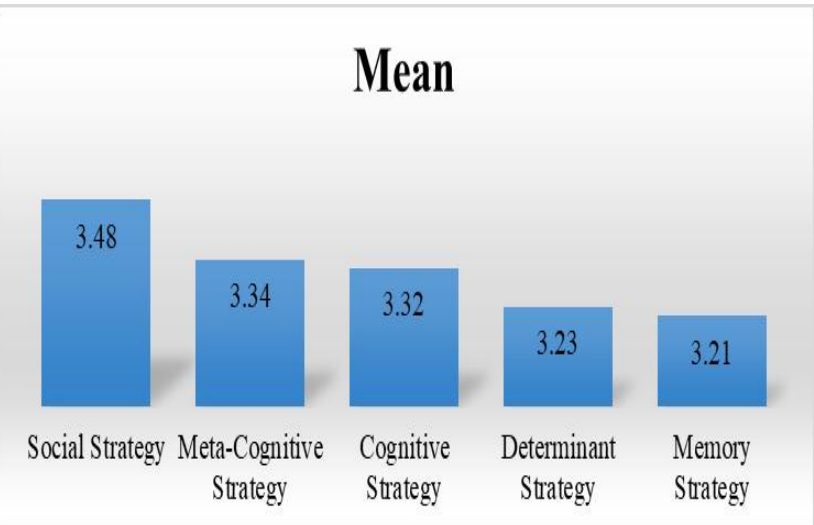

Figure 1: Strategies preferred by participants

RQ2: Is there any gender difference in the pattern and frequency of strategy use?

As can be seen in the Table 4, there was a big difference in the frequency of strategy use between male and female first year English major students.

Table 4: Use of VLS according to gender

\begin{tabular}{|l|l|l|l|l|l|l|} 
Strategy Type & Mean & SD & Rank & Mean & SD & Rank \\
\hline Meta-Cognitive Strategy & 3.19 & 0.868 & 2 & 3.49 & 0.623 & 3 \\
\hline Social Strategy & 3.43 & 1.105 & 1 & 3.53 & 1.074 & 2 \\
\hline Determinant Strategy & 3.07 & 0.760 & 4 & 3.39 & 0.538 & 4 \\
\hline Cognitive Strategy & 3.11 & 0.861 & 3 & 3.54 & 0.679 & 1 \\
\hline Memory Strategy & 3.04 & 0.714 & 5 & 3.37 & 0.520 & 5 \\
\hline
\end{tabular}

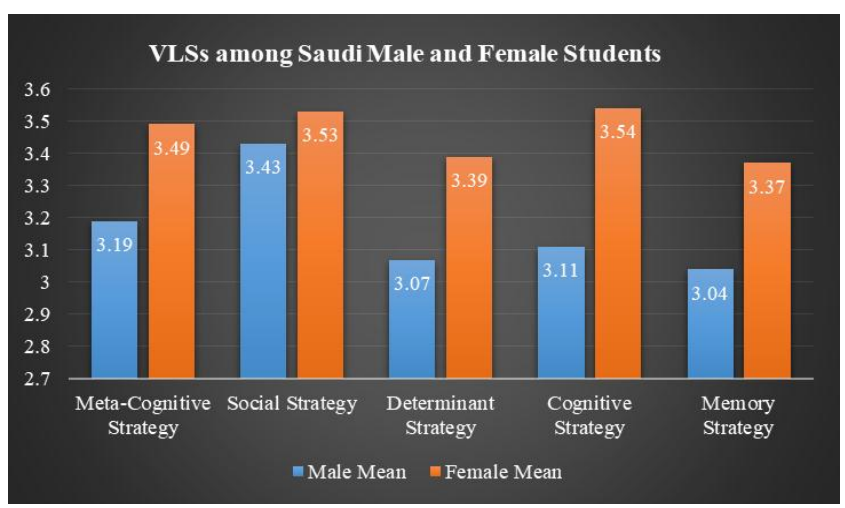

Figure 2: Main strategies used by participants according to gender

Table 4 and Figure 2 show all the five main strategies used by the participants of this study according to gender. Clearly, female students show a higher use of VLS compared to the male students. The highest frequency of use among female students was in the social strategy and cognitive strategy $(\mathrm{M}=3.53$, and $\mathrm{M}=3.54)$ while their male counterparts showed the highest frequency use in the social strategy and metacognitive strategy $(\mathrm{M}=3.43$ and $\mathrm{M}=$ 3.19). However, it can be seen that both genders prefer social strategies as a VLS.

An independent samples t-test was conducted for each main strategy of the questionnaire to calculate the factor scores for the construct VLS dimension. The process required the performance of a series of six independent samples t-tests on the scores to specify whether male and female Saudi first year students varied significantly. The $t$-test results are presented in Table 5 . 
Table 5: Independent Samples $t$-test for Use of VLS and Gender

\begin{tabular}{|c|c|c|c|c|c|c|c|c|}
\hline Dimension & $G$ & $\mathrm{~N}$ & $\mathrm{M}$ & SD & df & $t(-)$ & PV & $\mathrm{S}$ \\
\hline \multirow{2}{*}{$\begin{array}{l}\text { Meta-Cognitive } \\
\text { Strategy }\end{array}$} & $\mathrm{M}$ & 32 & 3.2 & 0.9 & \multirow{2}{*}{60} & 1.5 & \multirow{2}{*}{0.13} & \multirow[b]{2}{*}{ ns } \\
\hline & $\mathrm{F}$ & 30 & 3.5 & 0.6 & & 1.6 & & \\
\hline \multirow{2}{*}{ Social Strategy } & $\mathrm{M}$ & 32 & 3.4 & 1.1 & \multirow{2}{*}{60} & 0.3 & \multirow{2}{*}{0.73} & \multirow{2}{*}{ ns } \\
\hline & $\mathrm{F}$ & 30 & 3.5 & 1.1 & & 0.3 & & \\
\hline \multirow{2}{*}{$\begin{array}{l}\text { Determinant } \\
\text { Strategy }\end{array}$} & $\mathrm{M}$ & 32 & 3.1 & 0.8 & \multirow{2}{*}{60} & 10 & \multirow{2}{*}{0.07} & \multirow[b]{2}{*}{ ns } \\
\hline & $\mathrm{F}$ & 30 & 3.4 & 0.5 & & 1.9 & & \\
\hline \multirow{2}{*}{$\begin{array}{l}\text { Cognitive Strat- } \\
\text { egy }\end{array}$} & $\mathrm{M}$ & 32 & 3.1 & 0.9 & \multirow{2}{*}{60} & 2.1 & \multirow{2}{*}{0.04} & \multirow{2}{*}{$\mathrm{S}^{*}$} \\
\hline & $\mathrm{F}$ & 30 & 3.5 & 0.7 & & 2.2 & & \\
\hline \multirow{2}{*}{$\begin{array}{l}\text { Memory Strate- } \\
\text { gy }\end{array}$} & $\mathrm{M}$ & 32 & 3.1 & 0.7 & \multirow{2}{*}{60} & 2.0 & \multirow{2}{*}{0.05} & \multirow{2}{*}{$\mathrm{S}^{*}$} \\
\hline & $\mathrm{F}$ & 30 & 3.4 & 0.5 & & 2.1 & & \\
\hline \multirow{2}{*}{ VLSs } & $M$ & 32 & 3.2 & 0.7 & \multirow{2}{*}{60} & \multirow{2}{*}{1.9} & \multirow{2}{*}{0.06} & \multirow{2}{*}{$\mathrm{ns}$} \\
\hline & $\mathrm{F}$ & 30 & 3.3 & 0.5 & & & & \\
\hline
\end{tabular}

N-B: $\mathrm{G}=$ Group; $\mathrm{PV}=\mathrm{P}$ value; $\mathrm{M}=$ Male; $\mathrm{F}=$ Female; $\mathrm{df}=$ difference; $\mathrm{S}=$ Status; $\mathrm{t}=t$-test.

Of the five main VLS, only two strategies (cognitive and memory strategy) were found to differ significantly between the two genders. The $t$-test results showed a statistically significant difference in the cognitive strategies for females $(\mathrm{M}=3.54, \mathrm{SD}=.68)$ and males $(\mathrm{M}=3.12, \mathrm{SD}=.68) ; \mathrm{t}(-2.51)=4.760, \mathrm{P}=0.035$. The $\mathrm{t}$-test results also showed a statistically significant difference in the memory strategies for females $(\mathrm{M}=3.37, \mathrm{SD}=.52)$ and males $(\mathrm{M}$ $=3.05, \mathrm{SD}=.71) ; \mathrm{t}(-2.04)=4.760, \mathrm{P}=0.045$. Females appeared to have a higher use of cognitive and memory vocabulary learning strategies when compared to their male counterparts. The respondents did not differ significantly in the other VLS although female students did exhibit a slightly higher score on the use of VLS compared to the male students.

\section{Conclusion}

The results of this study indicate that the most frequently used strategies by participants were "I try to remember the word by repeating it several times," "I try to guess the meaning of the word from text/context" and "I learn new words when I interact with native-speakers." On the other hand, among the least frequently used strategies were "I ask my English instructor to check my flash cards or word list," "I use monolingual dictionary (EnglishEnglish)" and "I use semantic feature grids".

The findings of this study also show that of the five main vocabulary learning strategies, only two strategies (cognitive and memory strategy) were found to differ significantly between male and female students. Female students appeared to have a higher use of cognitive and memory vocabulary learning strategies when compared to their male counterparts.

Findings of this study indicate that teachers need to train learners on the use of VLS. It is essential that the teacher inform the students about the benefits of the VLS, how it can support their language learning, and what benefits they get from doing it. In this way, the students will be more motivated to intergrate VLS in their language acquisition. The main aim of the VLS is to establish learner autonomy in the language learning process so that they can acquire new vocabulary independently. As mentioned, EFL learners should be familiar with diverse techniques and ways to learn vocabulary and ultimately need to be able to acquire vocabulary on their own inside and outside the classroom, thus becoming independent and autonomous language learners. However, it was not the case for the students of this study. Findings of this study show that the participants did not utilize as much VLS.

Teachers should also encourage and train learners to use a variety of VLS in order to have a better outcome of vocabulary acquisition. It is also important for teachers to understand that all the VLS will not be suitable for every learner. That is why, he should provide enough opportunities for the learners to explore different strategies of vocabulary learning and allow learners to choose what is most suitable for them. Many scholars have pointed out various factors that influence a learner's choice of VLS. The more teachers know about such factors, the better they will be in designing lessons to cater to the different needs of students.

Additionally, the results emphasise the fact that training on using the appropriate strategy for using a new word should be provided by the teachers. Learners would benefit from training on how various vocabulary learning strategies could benefit their vocabulary acquisition. Moreover, both the EFL teachers and learners have to understand the value of extensive training in vocabulary learning strategies and on how learners could benefit from them.

The study concludes that the more strategies of vocabulary learning a learner utilises, the the better he becomes in his language acquisition. The researcher thus recommends teachers to provide VLS training in order to create independent and efficient language learners.

\section{References}

[1] Knight, S., "Dictionary use while reading: The effects on comprehension and vocabulary acquisition for students of different verbal abilities", The Modern Language Journal, 78 (2), (1994): 81-107

[2] Sun, X. M., "Review of L2 vocabulary acquisition researches at home and abroad", Language Teaching and Research, 25 (4), (2007): 54-62.

[3] Levenston, E., "Second language acquisition: issues and problems", Interlanguage Studies Bulletin, Utrecht 4, (1979): 147-60

[4] Schmitt, N., and McCarthy, M., "Vocabulary: Description, acquisition and pedagogy", Cambridge University Press, (1997).

[5] Gu, P.Y., "Learning strategies: Prototypical core and dimensions of variation", AIS St Helens, Centre for Research in International Education, (2005).

[6] Nation I.S., Paul., "Learning Vocabulary in Another Language", Cambridge: Cambridge University Press, (2001).

[7] Fan, M.Y., "Frequency of use, perceived usefulness, and actual usefulness of second language vocabulary strategies: A study of Hong Kong learners", The Modern Language Journal, 87 (2), (2003): 222-41.

[8] Gu P.Y., "Vocabulary learning in a second language: Person, task, context and strategies", TESL-EJ, 7 (2), (2003): 1-25.

[9] Oxford, R.L., "Toward a more systematic model of L2 learner autonomy", Learner autonomy across cultures, (2003): 75-91.

[10] Alhaysony, M., "Vocabulary discovery strategy used by Saudi EFL students in an intensive English language learning context", International journal of linguistics, 27 (2), (2012): 518-35.

[11] Amirian, S., and Heshmatifar, Z., "The impact of using electronic dictionary on vocabulary learning and retention of Iranian EFL learners", International Journal of Research Studies in Educational Technology, 2 (1), (2013): 35-44.

[12] Kudo, Y., "L2 vocabulary learning strategie", Unpublished doctoral thesis, University of Hawaii, Manoa, Hawaii, (1999).

[13] Jun-Eon P. Korean EFL Learners' Vocabulary Learning Strategies. English Teaching, 56(4), (2001): 3-30.

[14] Al-Nujaidi, A.H., "Vocabulary learning strategies of Saudi first-year university students", Doctoral dissertation, Colorado State University, (2000).

[15] Kobayashi, C., Vocabulary learning strategies of Japanese students of English in the United States", Doctoral dissertation, Colorado State University, (2000).

[16] Lawson, M.J, and Hogben D., "The vocabulary- learning strategies of foreign- language students", Language learning, 46 (1), (1996): 101-35.

[17] Sahbazian, S., "Perceived vocabulary learning strategies of Turkish university students", Unpublished PhD thesis, Oklahoma State University, Oklahoma, USA (2004).

[18] Brantmeier, C., "Does gender make a difference? Passage content and comprehension in second language reading", Reading in a foreign language, 15 (1), (2003).

[19] Young, Dolly, J., and Rebecca O., "A Gender-Related Analysis of Strategies Used To Process Written Input in the Native Language and a Foreign Language", Applied language learning, 8 (1), (1997): 43-73. 
[20] Catalan, and Rosa, M.J., "Sex differences in L2 vocabulary learning strategies", International Journal of Applied Linguistics, 13 (1), (2003): 54-77.

[21] Lin, Jie, and Fenglan Wu., "Differential Performance by Gender in Foreign Language Testing", Paper presented at the Annual Meeting of the National Council on Measurement in Education, Chicago, (2004).

[22] Lynn, Richard, David M. Fergusson, and L. John Horwood., "Sex differences on the WISC-R in New Zealand", Personality and Individual Differences, 39 (1), (2005): 103-114.

[23] Edelenbos, P, and Marja, P.V., "The assessment of a foreign language at the end of primary (elementary) education", Language Testing, 17 (2), (2000): 144-162.

[24] Nyikos, M, "Sex- Related Differences in Adult Language Learning: Socialization and Memory Factors", The Modern Language Journal 74 (3), (1990): 273-287.

[25] Sunderland, J., "Theorizing gender perspectives in foreign and second language learning", In Gender perspectives on vocabulary in foreign and second languages, Palgrave Macmillan, London, (2010): 1-19.

[26] Catalán, Rosa, M.J., and Melania, T.G., "The receptive vocabulary of English foreign language young learners", Journal of English Studies, 5, (2005): 173-192.

[27] Meara, P., and Tess, F., "Lex30: An improved method of assessing productive vocabulary in an L2", System, 28 (1), (2000): 19-30.

[28] Jiménez, Rosa, M., and Soraya, M., "L2 word associations and the variable sex: An outline according to an electronic tool", In Proceedings of the 27th International AEDEAN Conference. Salamanca: Editorial Ambos Mundos, (2004).

[29] Catalán, Rosa, M. J., and Julieta, O.A., "Girls' and boys' lexical avaliability in EFL", ITL International Journal of Applied Linguistics, 158, (2009): 57-76.

[30] Jiménez, R. M., and María, R., "Gender perspectives on vocabulary in foreign and second language", Basingstoke: Palgrave MacMilla, (2010).

[31] Grace, C.A., "Gender differences: Vocabulary retention and access to translations for beginning language learners in CALL", The Modern Language Journal, 84 (2), (2000): 214-224.

[32] Ahmed, M.O., "Vocabulary learning strategies", Beyond words, (1989): 3-14.

[33] Ruutmets, K., "Vocabulary learning strategies in studying English as a foreign language", PhD dissertation, (2005).

[34] Lee, S., and Min, M., "A study on Korean high school students' use of vocabulary learning strategies", English Teaching, 61 (2), (2006): 115-137 